Cahiers $d u$ MONDE RUSSE

\section{Cahiers du monde russe}

Russie - Empire russe - Union soviétique et États indépendants

$43 / 4 \mid 2002$

Intellectuels et intelligentsia

\title{
David Schimmelpenninck van der Oye, Toward the rising sun
}

\author{
Marlène Laruelle
}

\section{OpenEdition}

Journals

Édition électronique

URL : https://journals.openedition.org/monderusse/4019

DOI : 10.4000/monderusse.4019

ISSN : $1777-5388$

\section{Éditeur}

Éditions de l'EHESS

\section{Édition imprimée}

Date de publication : 30 décembre 2002

Pagination : 703-705

ISBN : 2-7132-1796-2

ISSN : $1252-6576$

Référence électronique

Marlène Laruelle, "David Schimmelpenninck van der Oye, Toward the rising sun », Cahiers du monde russe [En ligne], 43/4 | 2002, mis en ligne le 17 juin 2009, consulté le 03 septembre 2022. URL : http:// journals.openedition.org/monderusse/4019; DOI : https://doi.org/10.4000/monderusse.4019

Ce document a été généré automatiquement le 3 septembre 2022

Tous droits réservés 


\title{
David Schimmelpenninck van der Oye, Toward the rising sun
}

\author{
Marlène Laruelle
}

\section{RÉFÉRENCE}

David SCHIMMELPENNINCK VAN DER OYE, Toward the rising sun. Russian

ideologies of empire and the path to war with Japan. Dekalb, Northern Illinois

University Press, 2001, $329 \mathrm{p}$.

1 L'ouvrage de David Schimmelpenninck van der Oye s'intéresse à l'histoire et aux soubassements idéologiques qui ont conduit à la guerre russo-japonaise de 1905. L'auteur s'inscrit dans un courant de recherche contemporain qui tend à combler une lacune en ce qui concerne les relations de la Russie avec l'Asie, bien moins connues que celles avec les pays occidentaux. Il se fonde sur une très large bibliographie et un accès approfondi à des documents inédits (notes de service, mémorandums, mémoires) conservés dans les archives du ministère russe des Affaires étrangères. On appréciera tout particulièrement la reproduction de plusieurs caricatures d'époque.

2 Le livre est divisé en deux parties, la première portant sur les idéologies impériales russes du tournant du siècle, la seconde sur les événements qui ont provoqué la guerre de 1905. L'auteur passe tout d'abord en revue les principaux courants idéologiques qui se sont intéressés à la mission russe en Orient après le fameux « Grand Tour » de Nicolas II en Asie (1892). Le dernier tsar s'est en effet révélé bien plus attiré par l'Orient que son père - davantage tourné vers les questions européennes -, subissant l'influence de nombreux intrigants défendant des intérêts souvent très personnels en Asie. Dès les années 1880, l'un des grands explorateurs de l'Asie centrale et du Tibet, Nikolaj Prževal 'skij, proche du tsarevitch, prône un impérialisme "blanc» de la Russie en Chine. Quelques années plus tard, de tels projets revoient le jour, sous un angle beaucoup plus théorisé, chez le prince $\mathrm{E}$. Uhtomskij, ancien précepteur du tsarevitch, ami intime de Witte et principal idéologue de l'expansion russe en Asie entre 1895 et 1905. Tous deux 
espèrent un soulèvement des populations bouddhistes et musulmanes présentes au Xinjiang, au Tibet, en Mongolie et en Mandchourie contre la dynastie chinoise des Qing et en faveur d'un rattachement à l'empire russe. L'idée d'une domination politique des Romanov en Extrême-Orient existe également au sein même des instances étatiques : on la retrouve dans la théorie d'une possible « pénétration pacifique » de l'Asie par la Russie chez Witte et dans la thématique du "péril jaune» chez le ministre de la Guerre Aleksandr Kuropatkin.

3 La seconde partie du livre est consacrée à la genèse de la guerre russo-japonaise : des choix stratégiques peu sûrs en Mandchourie et en Corée, une diplomatie confuse et contradictoire depuis la guerre des Boxers en 1900, de multiples personnalités opposées engagées dans les pourparlers avec le Japon, etc. Deux partis s'affrontent à SaintPétersbourg, l'un prudent et prêt à renoncer à la Corée (Witte, Pobedonoscev, Kuropatkin et le ministre des Affaires étrangères Lamsdorff), l'autre belliqueux, regroupant Nicolas II, le grand-duc Aleksandr Mihailovič, Plehve et surtout l'intrigant A. Bezobrazov, qui dispose d'une concession forestière dans le Ya-Lou en Corée et obtient du tsar le titre de secrétaire d'État de la Commission pour les affaires d'Extrême-Orient. Le livre rappelle enfin qu'outre la politique du « Grand Jeu » avec l'empire britannique en Asie, l'influence allemande n'a pas été des moindres : l'empereur Guillaume II n'a cessé d'encourager son cousin à s'engager en Extrême-Orient dans l'espoir de libérer la scène européenne de la présence russe.

4 L'auteur apporte un nouvel éclairage sur les sous-entendus idéologiques qui ont donné à l'opinion publique et aux élites russes l'impression que cette guerre serait courte et nécessairement victorieuse. Ainsi, des journaux conservateurs comme Graždanin, Novoe vremja ou les Sankt-Peterburgskie vedomosti n'ont cessé d'accréditer la thèse d'une conquête facile et sans résistance de l'Extrême-Orient. Les cercles dirigeants, en partie noyautés par des milieux affairistes, ont repris à leur compte les discours idéologiques sur l'impatience des peuples de Chine à passer sous la domination du « tsar blanc ». L'idée qu'il fallait répondre au "péril jaune » en Sibérie par la conquête d'une partie de l'empire du Milieu semble elle aussi avoir été en arrière-fond des choix stratégiques faits par le pouvoir russe.

5 La conclusion cherche à lier l'étude des idéologies avec celle des relations internationales en essayant de mesurer l'impact des constructions théoriques sur les événements, un parti pris méthodologique particulièrement intéressant. On aurait souhaité voir cette interaction encore plus développée dans le plan même du livre qui sépare peut-être trop le discours des intellectuels et l'action politique et stratégique du pouvoir. L'ouvrage apporte un éclairage neuf sur un moment fondateur de la Russie contemporaine : ce n'est en effet sûrement pas un hasard si la révolution de 1905 a lieu alors que s'annonce la première défaite "blanche» face à un "peuple de couleur». Il permet également de redonner aux idéologies impériales russes une place de choix dans la réflexion sur l'identité nationale et révèle l'influence de milieux intellectuels certes sociologiquement restreints mais symboliquement influents. Le livre de Schimmelpenninck constitue donc un ouvrage de référence aussi bien en histoire des idées qu'en histoire des relations internationales pour la Russie du tournant du siècle. 